\title{
p16INK4A expression is frequently increased in periorbital and ocular squamous lesions
}

Peter J. Kobalka ${ }^{1,3^{*}}$, Jean-Paul Abboud ${ }^{2}$, Xiaoyan Liao ${ }^{1}$, Karra Jones ${ }^{1}$, Bradford W. Lee², Bobby S. Korn², Don O. Kikkawa ${ }^{2}$ and Jonathan H. Lin ${ }^{1,2}$

\begin{abstract}
Background: p16 expression is a well established biomarker of cervical dysplasia and carcinoma arising from high risk human papilloma virus infection. Increased p16 expression is also seen in squamous neoplasms arising at other sites, including head, neck, and oropharyngeal tract. Squamous lesions are also frequently encountered at ocular surface and peri-orbital skin sites, but the prevalence of increased p16 expression in these lesions has been poorly studied.
\end{abstract}

Methods: We retrospectively surveyed 13 ocular surface and 16 orbital squamous lesions biopsied at UC San Diego Healthcare System and VA San Diego Healthcare System for p16 expression by immunohistochemistry. These cases included ocular surface lesions with diagnoses of conjunctival intraepithelial neoplasm (CIN) and squamous cell carcinoma in situ. Peri-orbital eyelid biopsies included lesions with diagnoses of SCCis and invasive squamous cell carcinoma. We performed multivariate logistic regression, followed by student's T-test or Fisher's exact test to determine if there were statistically significant associations between p16 immunoreactivity and patient age, gender, diagnosis, and ethnicity. Statistical significance was defined as $p<0.05$.

Results: We found an unexpectedly large prevalence of strong nuclear and cytoplasmic p16 immunoreactivity in our cases. Almost all of the ocular surface squamous lesions were diffusely positive for p16 expression (12/13). All of the periorbital lesions showed diffuse p16 immunoreactivity (16/16). Altogether, 28/29 lesions tested showed strong and diffuse p16 expression. We found no statistically significant correlation between p16 expression and patient age, gender, ethnicity, or diagnosis. In 6 of the peri-orbital biopsies, we had sufficient tissue to assess high-risk HPV expression by in situ hybridization. Interestingly, all of these cases were negative for HPV, despite strong p16 expression.

Conclusion: Strong p16 expression was observed in virtually all of the ocular surface and peri-orbital squamous neoplasms in our study. The relationship between p16 expression and HPV infection in ocular surface and peri-orbital sites requires further investigation.

\section{Background}

HPV is linked to development of cervical, anogenital, head/neck, and lung squamous lesions and carcinomas [1-5]. Increased $\mathrm{p} 16^{\mathrm{INK4A}}$ expression is seen in HPVassociated squamous lesions, and the strength and subcellular staining pattern of p16 immunohistochemical reactivity correlates closely with the degree of dysplasia,

\footnotetext{
* Correspondence: pkobalka@ucsd.edu

'Department of Pathology, University of California San Diego and VA San

Diego Healthcare System, San Diego, CA, USA

${ }^{3}$ Department of Pathology, School of Medicine, UC San Diego, 9500 Gilman

Dr., La Jolla, CA 92093-0612, USA

Full list of author information is available at the end of the article
}

with higher-grade lesions showing intense, diffusely positive nuclear and cytoplasmic p16 expression in affected squamous cells [6-14]. Increased p16 ${ }^{\mathrm{INK} 4 \mathrm{~A}}$ expression arises from neutralization of cellular p53 and pRb tumor suppressor proteins by HPV E6 and E7 oncogenes in infected cells $[15,16]$. Low-risk HPV subtypes typically show less $\mathrm{p} 16^{\mathrm{INK} 4 \mathrm{~A}}$ induction because they produce E6 and E7 viral oncogenes with lower ability to neutralize endogenous tumor suppressors [17]. Therefore, $\mathrm{p} 16^{\mathrm{INK} 4 \mathrm{~A}}$ expression is commonly employed as a surrogate marker of infection by high-risk HPV subtypes.

Malignant squamous lesions of ocular and peri-ocular structures include conjunctival intraepithelial neoplasia 
(CIN) to frank invasive squamous cell carcinoma (SCC). HPV has also been detected in prior studies of ocular and peri-ocular squamous lesions and suggested to contribute to the pathogenesis of squamous lesions in the eye [18-21]. However, very few studies have examined p16 expression in squamous lesions resected from the eye, and there have been conflicting findings from these reports. In a cohort of HIV seropositive patients in Africa, Mwololo and colleagues findings found strong p16 immunoreactivity in $67 \%$ (39 of 58) of SCC conjunctival biopsies [22]. However, in a study of ocular surface and conjunctival squamous lesions performed in Australia, Woods and colleagues found p16 immunoreactivity in only $6.5 \%$ (3 of 46) ocular surface squamous neoplasia biopsies and $12.5 \%$ (3 of 24) conjunctival SCCs [23]. Interestingly, p16 immunoreactivity completely correlated with HPV detection by PCR in this study [23].

In our study, we hypothesized that p16 immunoreactivity was significantly increased in malignant ocular squamous lesions. To examine this, we examined 29 ocular surface and periorbital squamous lesions excised at our institution that comprised malignant (CIN and SCC) ocular squamous neoplasms. We performed p16 IHC analysis on all lesions, followed by HPV ISH on a subset of p16-positive cases. We compared the histopathologic and molecular findings with clinical data to identify potential significant correlations between p16 expression in ocular squamous lesions and clinical characteristics of our patient population.

\section{Methods}

\section{Tissue specimens}

We examined a total of 29 ocular surface and periorbital eyelid squamous lesion cases retrieved from the VA San Diego and UCSD Medical Center between July 2010May 2014. These cases were routinely fixed in $10 \%$ formalin and embedded in paraffin. H\&E (hematoxylin and eosin)-stained slides were reviewed and classified by an ophthalmologic pathologist. All lesions with a diagnosis of CIN or SCC (in situ or invasive) were included in this study. The study was approved by the Institutional Review Boards at UCSD and VA San Diego.

\section{p16 immunohistochemistry}

Immunohistochemical studies for p16 were performed using a Ventana Benchmark Ultra. The p16 antibody used was a monoclonal mouse antibody (clone JC8, Santa Cruz Biotechnology; dilution 1:80). Lesions were considered positive for $\mathrm{p} 16$ when both cytoplasmic and nuclear staining was observed in epithelial cells. Staining in dendritic cells and non-epithelial cells was disregarded.

\section{HPV in-situ hybridization}

In-situ hybridization was performed on formalin-fixed, paraffin-embedded tissue by ARUP laboratories (Salt
Lake City, Utah). The test was run on a Ventana Bentana Benchmark Ultra (Ventana Medical Systems, Inc), using the INFORM HPV II FAMILY 6 (ASR) probe. A probe set for high-risk HPV $[16,18]$ were employed (catalog \#2002899). This test is CLIA-certified for clinical use and widely performed for evaluation of high risk HPVs in suspicious tissue biopsies.

\section{Statistical analysis}

Statistical analysis was performed on CINs and SCCs. The correlation between p16 immunoreactivity and patient's age, gender, diagnosis, and ethnicity was first analyzed by Multivariate Logistic Regression using SAS 9.3, followed by individual student's T-test (for age difference) or Fisher's exact test (for gender, ethnicity, or diagnosis differences). A difference was considered statistical significant if $\mathrm{p}<0.05$.

\section{Results}

\section{p16 expression by immunohistochemistry}

A total of 29 cases were evaluated for p16 immunoreactivity (Table 1). Patients ranged in age from 37 to 88 and included 11 women and 18 men with White ethnicity (by self-report) being the most common. The majority of patients were seronegative for HIV (27/29). Negative p16 immunoreactivity was defined as lacking cytoplasmic and nuclear labeling of the squamous keratinocytes (Fig. 1), while p16 was considered positive when there was both strong cytoplasmic and nuclear labeling of dysplastic keratinocytes in the lesion. By this criteria, 28 of the 29 cases showed strong p16 immunoreactivity of dysplastic squamous cells (Figs. 2, 3, and 4 and Table 1 ). When grouped by diagnosis, all of the SCCs (20/20) were p16-positive (Figs. 2 and 4, Table 1), and 8/9 CINs were p16-positive (Table 1).

\section{HPV detection by in-situ hybridization}

HPV in-situ hybridization against HPV genotypes 6, 11, 16 , and 18 was performed on 6 lesions in total that were intensely and diffusely positive for $\mathrm{p} 16$ by immunohistochemistry. Of six squamous cell carcinomas tested, none were positive for HPV. CIN cases had insufficient remaining tissue in the blocks to perform the HPV ISH assay due to the small size of the conjunctival biopsy.

\section{Clinical and statistical correlation}

We next examined if positive p16 expression correlated with pathologic type of squamous lesion, patient age (less than or older than 50), patient gender, and ethnicity (White, Hispanic) by multivariate logistic regression, Student's t-test, and Fischer's exact test. No significant differences were seen between the pathologic types of lesions tested and $\mathrm{p} 16$ positivity $(\mathrm{p}>0.05)$. In addition, 
Table 1 Patient clinico-pathologic profiles

\begin{tabular}{|c|c|c|c|c|c|c|c|c|}
\hline Age & Sex & Anatomic site & Ethnicity & HIV status & Pathologic diagnosis & P16 immunoreactivity & P16 IHC staining pattern & $\mathrm{ISH}$ \\
\hline 71 & M & Eyelid & Unknown & Negative & Invasive SCC & Positive & Nuc and cyto & a \\
\hline 85 & M & Eyelid & White & Negative & Invasive SCC & Positive & Nuc and cyto & a \\
\hline 59 & M & Eyelid & White & Negative & SCC in situ & Positive & Nuc and cyto & a \\
\hline 46 & M & Conjunctiva & White & Negative & invasive SCC & Positive & Nuc and cyto & a \\
\hline 78 & $\mathrm{~F}$ & Eyelid & White & Negative & SCC in situ & Positive & Nuc and cyto & a \\
\hline 37 & M & Conjunctiva & Hispanic & Negative & SCC in situ & Positive & Nuc and cyto & Negative \\
\hline 88 & $\mathrm{~F}$ & Eyelid & White & Negative & SCC in situ & Positive & Diffuse nuc and cyto & Negative \\
\hline 89 & $\mathrm{~F}$ & Eyelid & White & Negative & SCC in situ & Positive & Diffuse nuc and cyto & a \\
\hline 67 & $\mathrm{~F}$ & Eyelid & White & Negative & Invasive SCC & Positive & Diffuse nuc and cyto & a \\
\hline 77 & M & Conjunctiva & White & Positive & $\mathrm{CIN}$ & Positive & Diffuse nuc and cyto & a \\
\hline 76 & $\mathrm{~F}$ & Eyelid & White & Negative & SCC in situ & Positive & Diffuse nuc and cyto & Negative \\
\hline 47 & M & Cornea & White & Negative & SCC in situ & Positive & Diffuse nuc and cyto & a \\
\hline 45 & $\mathrm{~F}$ & Eyelid & White & Negative & Invasive SCC & Positive & Diffuse nuc and cyto & Negative \\
\hline 76 & $\mathrm{~F}$ & Eyelid & White & Negative & SCC in situ & Positive & Scattered nuc and cyto & a \\
\hline 61 & M & Eyelid & White & Negative & Invasive SCC & Positive & Focal nuc and cyto & Negative \\
\hline 88 & $\mathrm{~F}$ & Eyelid & White & Negative & Invasive SCC & Positive & Diffuse nuc and cyto & Negative \\
\hline 88 & $\mathrm{~F}$ & Eyelid & White & Negative & SCC in situ & Positive & Patchy nuc and cyto & a \\
\hline 88 & $\mathrm{~F}$ & Eyelid & White & Negative & SCC in situ & Positive & Focal nuc and cyto & a \\
\hline 45 & M & Eyelid & White & Negative & SCC in situ & Positive & Diffuse nuc and cyto & a \\
\hline 65 & M & Eyelid & Unknown & Negative & SCC in situ & Positive & Diffuse nuc and cyto & a \\
\hline 76 & M & Conjunctiva & Hispanic & Negative & $\mathrm{CIN}$ & Positive & Focal nuc and cyto & a \\
\hline 32 & $\mathrm{~F}$ & Conjunctiva & White & Negative & $\mathrm{CIN}$ & Positive & Scattered nuc and cyto & a \\
\hline 56 & M & Conjunctiva & Hispanic & Positive & $\mathrm{CIN}$ & Positive & Scattered nuc and cyto & a \\
\hline 46 & M & Cornea & White & Negative & $\mathrm{CIN}$ & Positive & Diffuse nuc and cyto & a \\
\hline 64 & M & Cornea/conjunctiva & Unknown & Negative & SCC in situ & Positive & Diffuse nuc and cyto & a \\
\hline 72 & M & Conjunctiva & White & Negative & $\mathrm{CIN}$ & Positive & Diffuse nuc and cyto & a \\
\hline 56 & M & Conjunctiva & White & Negative & $\mathrm{CIN}$ & Positive & Scattered nuc and cyto & a \\
\hline 40 & M & Conjunctiva & Hispanic & Positive & $\mathrm{CIN}$ & Negative & N/A & a \\
\hline 70 & M & Conjunctiva & White & Negative & $\mathrm{CIN}$ & Positive & Diffuse nuc and cyto & a \\
\hline
\end{tabular}

Nuc Nuclear, Cyto cytoplasmic

${ }^{\mathrm{a}}$ Not performed

there were no significant differences between p16 positivity and age, gender, ethnicity or diagnosis.

\section{Discussion}

Our study reveals a surprisingly high prevalence of p16 immunoreactivity in ocular squamous lesions from our patient population, but interestingly, these squamous lesions with strong p16 expression did not show HPV 6, 11,16 , and 18 genetic material by ISH. We discuss some potential causes for the increased p16 expression but low HPV infection observed in our study.

P16 immunoreactivity is well established as a biomarker for HPV infection in sites such as cervix, and the vast majority of HPV-associated cancers show increased p16 expression [12-14, 24, 25]. However, p16 induction has also been observed after inflammatory conditions, after total body irradiation, and with prolonged genomic damage, independent of HPV infection [26, 27] and in a recent study of bladder SCC, about $1 / 3$ of SCC cases showed p16 immunoreactivity but no HPV genetic material by in situ hybridization [28]. Similarly, increased p16 expression did not correlate with HPV infection in SCC from lung, skin and esophagus [29]. In our ocular squamous neoplasms, it is possible that increased p16 expression could arise from stresses other than HPV infection, and indeed, solar damage was previously proposed as a risk factor for increased HPV infection in eye disease [19].

Our HPV ISH test was performed by ARUP labs, using a commercially available limited HPV ISH probe against 


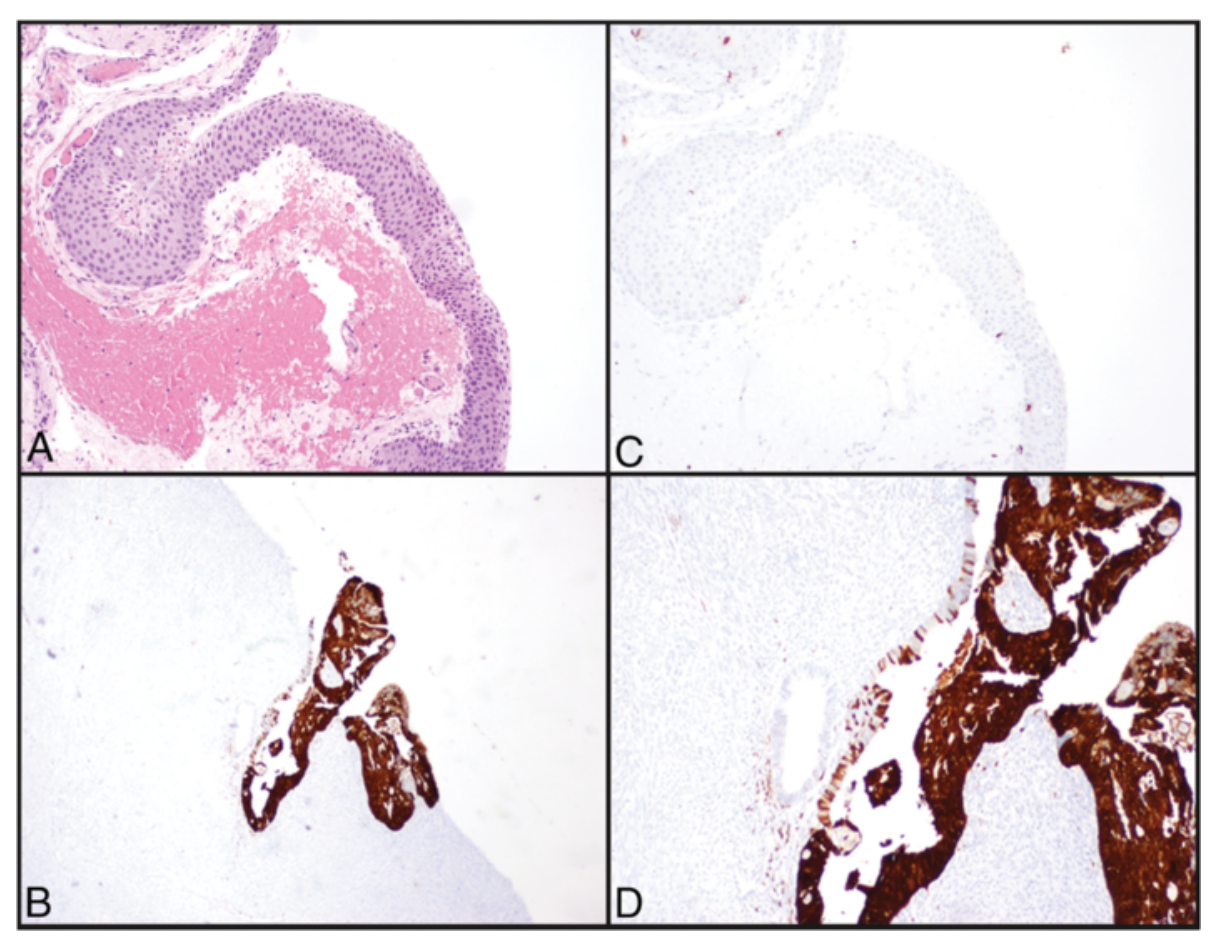

Fig. 1 a Histology of the negative control, taken from a pterygia (20x, magnification). c Immunohistochemical staining for p16 in the same case (20x magnification). Note the lack of staining in epithelial cells. b, d Positive control p16 immunohistochemical staining, taken from a squamous cell carcinoma in-situ from cervix ( $4 x$ and 20x, respectively). Note both cytoplasmic and nuclear reactivity

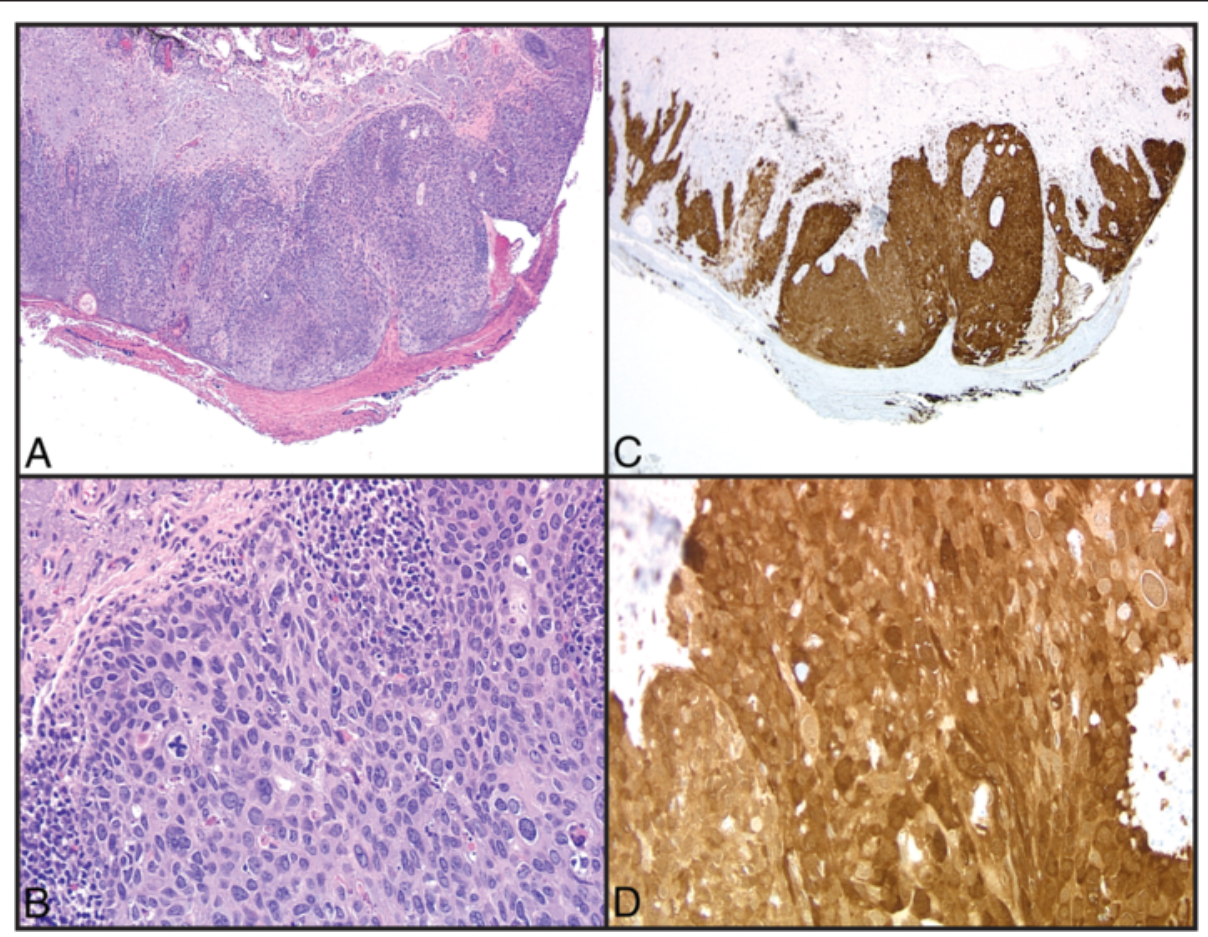

Fig. 2 a, b Histology of a squamous cell carcinoma in situ from eyelid biopsy (4x and 20x, respectively). c, d Immunohistochemical staining for p16 in the same case (4x and 20x, respectively). Note the extensive cytoplasmic and nuclear reactivity 


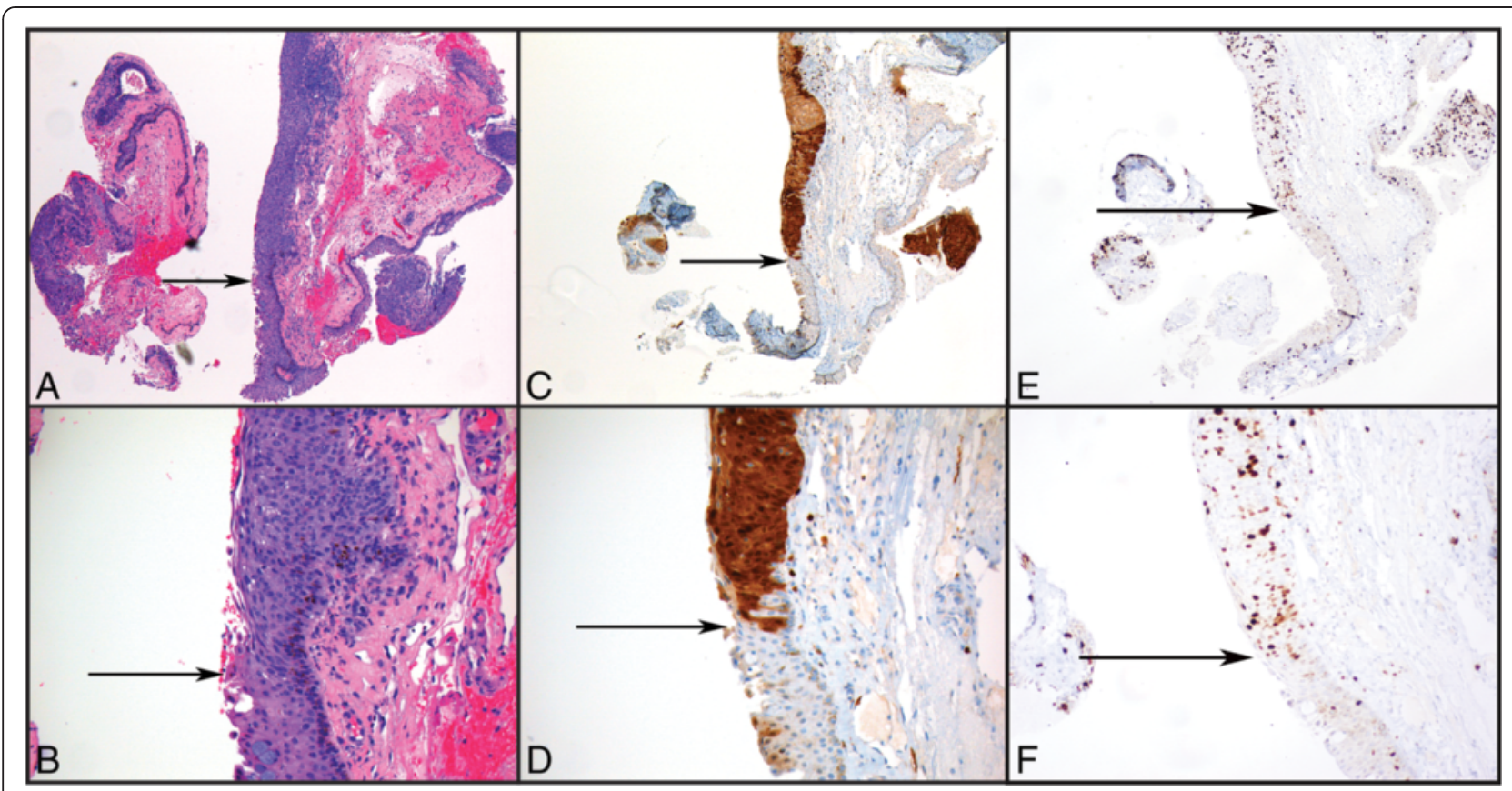

Fig. 3 a, b Histology of an in-situ squamous cell carcinoma of the conjunctiva from a patient with HIV (4x and 20x, respectively). c, $\mathbf{d}$ Immunohistochemical staining for p16 in the same case (4x and 20x, respectively). Note the lack of p16 staining in adjacent normal conjunctiva with goblet cells. Arrows mark the transition between normal and dysplastic epithelium. e, f Immunohistochemical staining for Ki-67 (MIB-1). Note full-thickness reactivity in dysplastic epithelium

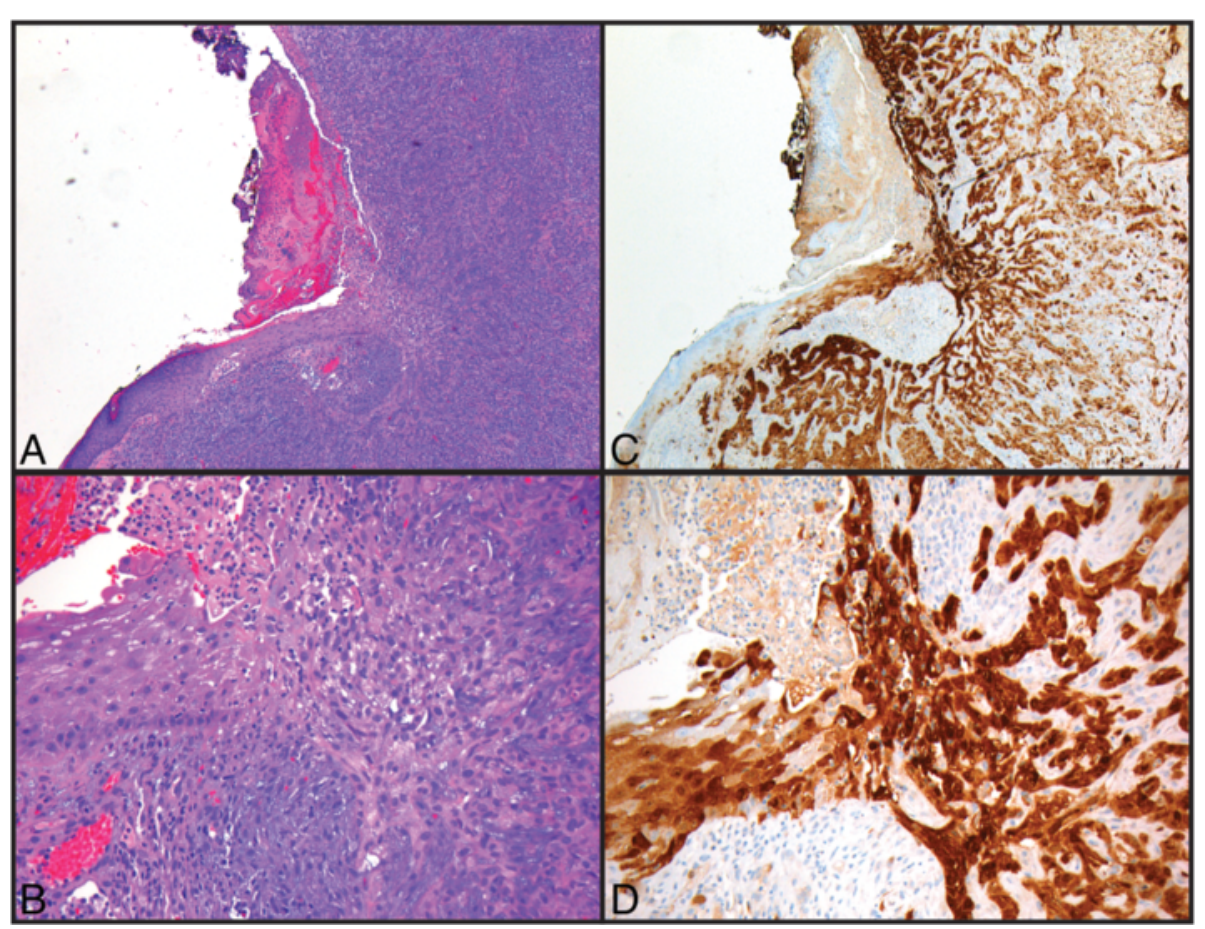

Fig. 4 a, b Histology of an invasive squamous cell carcinoma ( $4 x$ and $20 x$, respectively). c, d Immunohistochemical staining for p16 in the same case (4x and 20x, respectively). Note both cytoplasmic and nuclear reactivity 
HPV genotypes $6,11,16$, and 18 that is widely used to identify HPV infection in human tissue specimens. These HPV genotypes are widely observed in cervical squamous lesions but their trophism to other squamous sites is less clear. Ateenyi-Agaba and colleagues isolated several uncharacterized HPV genotypes from their conjunctival SCC lesions [21]. It remains possible that in our specimens, other HPV genotypes could be present and account for the increased p16 expression. A broader spectrum probe for more HPV genotypes could help reconcile p16 positive lesions that were initially negative [29].

HPV detection techniques vary in their sensitivity [30]. Our study employed a CLIA-approved ISH assay commonly used for cervical biopsies at our institution as a confirmatory test for HPV in p16 positive ocular squamous lesions. RT-PCR testing is more sensitive for HPV testing [31, 32], and, in one study of oropharyngeal SCCs, many ISH negative SCCs of the oropharynx were positive by PCR [33]. Repeat HPV testing by different methodologies may be required to identify HPV in cases with high clinical suspicion. Further follow-up studies using more sensitive and broader methodologies may be helpful to determine if p16 expression in ocular squamous lesions corresponds to HPV infection.

\section{Conclusion}

Our studies showed that p16 expression is frequently increased in malignant squamous lesions arising at the conjunctiva or adjoining eyelid.

\section{Competing interests}

The authors declare that they have no competing interests.

\section{Authors' contributions}

PJK searched slide logs for cases, took pictures, and drafted the manuscript. JPA worked on acquiring clinical information on cases, performing the surgical resections, and assisted in drafting the manuscript. $\mathrm{XL}$ focused on statistical analysis. KJ carried out figure and legend preparations. BWL worked on acquiring clinical information on cases, and performing the surgical resections. BSK worked on acquiring clinical information on cases and performing the surgical resections. DOK worked on acquiring clinical information on cases and performing the surgical resections. JHL conceived of the study, read the slides, and helped to draft the manuscript. All authors read and approved the final manuscript.

\section{Author details \\ ${ }^{1}$ Department of Pathology, University of California San Diego and VA San Diego Healthcare System, San Diego, CA, USA. ${ }^{2}$ Shiley Eye Center and Department of Ophthalmology, University of California San Diego and VA San Diego Healthcare System, San Diego, CA, USA. ${ }^{3}$ Department of Pathology, School of Medicine, UC San Diego, 9500 Gilman Dr., La Jolla, CA 92093-0612, USA.}

Received: 2 July 2015 Accepted: 28 August 2015

Published online: 24 September 2015

\section{References}

1. Stanley M. Pathology and epidemiology of HPV infection in females. Gynecol Oncol. 2010;117:S5-10.

2. Munoz N, Castellsague X, de Gonzalez AB, Gissmann L. Chapter 1: HPV in the etiology of human cancer. Vaccine. 2006;24 Suppl 3:S3/1-10.
3. Clavel CE, Nawrocki B, Bosseaux B, Poitevin G, Putaud IC, Mangeonjean CC, et al. Detection of human papillomavirus DNA in bronchopulmonary carcinomas by hybrid capture II: a study of 185 tumors. Cancer. 2000;88:1347-52.

4. Bohlmeyer T, Le TN, Shroyer AL, Markham N, Shroyer KR. Detection of human papillomavirus in squamous cell carcinomas of the lung by polymerase chain reaction. Am J Respir Cell Mol Biol. 1998;18:265-9.

5. Blitzer GC, Smith MA, Harris SL, Kimple RJ. Review of the clinical and biologic aspects of human papillomavirus-positive squamous cell carcinomas of the head and neck. Int J Radiat Oncol Biol Phys. 2014;88:761-70

6. Lesnikova I, Lidang M, Hamilton-Dutoit S, Koch J. p16 as a diagnostic marker of cervical neoplasia: a tissue microarray study of 796 archival specimens. Diagn Pathol. 2009;4:22.

7. Hu L, Guo M, He Z, Thornton J, McDaniel LS, Hughson MD. Human papillomavirus genotyping and p16INK4a expression in cervical intraepithelial neoplasia of adolescents. Mod Pathol. 2005;18:267-73.

8. Kumar V, Abbas AK, Aster JC. Robbins and Cotran pathologic basis of disease. Philadelphia, PA: Elsevier/Saunders; 2015.

9. Chen ZW, Weinreb I, Kamel-Reid S, Perez-Ordonez B. Equivocal p16 immunostaining in squamous cell carcinoma of the head and neck: staining patterns are suggestive of HPV status. Head Neck Pathol. 2012;6:422-9.

10. Murphy N, Ring M, Killalea AG, Uhlmann V, O'Donovan M, Mulcahy F, et al. p16INK4A as a marker for cervical dyskaryosis: CIN and cGIN in cervical biopsies and ThinPrep smears. J Clin Pathol. 2003;56:56-63.

11. Wang JL, Zheng BY, Li XD, Nokelainen $K$, Angstrom T, Lindstrom MS, et al. p16INK4A and p14ARF expression pattern by immunohistochemistry in human papillomavirus-related cervical neoplasia. Mod Pathol. 2005;18:629-37.

12. Klussmann JP, Gultekin E, Weissenborn SJ, Wieland U, Dries V, Dienes HP, et al. Expression of p16 protein identifies a distinct entity of tonsillar carcinomas associated with human papillomavirus. Am J Pathol. 2003;162:747-53.

13. Smith EM, Wang D, Kim Y, Rubenstein LM, Lee JH, Haugen TH, et al. P16INK4a expression, human papillomavirus, and survival in head and neck cancer. Oral Oncol. 2008;44:133-42.

14. Woo SB, Cashman EC, Lerman MA. Human papillomavirus-associated oral intraepithelial neoplasia. Mod Pathol. 2013;26:1288-97.

15. Dyson N, Howley PM, Munger K, Harlow E. The human papilloma virus-16 E7 oncoprotein is able to bind to the retinoblastoma gene product. Science. 1989;243:934-7.

16. Scheffner M, Huibregtse JM, Vierstra RD, Howley PM. The HPV-16 E6 and E6-AP complex functions as a ubiquitin-protein ligase in the ubiquitination of p53. Cell. 1993;75:495-505.

17. Krishnappa P, Mohamad IB, Lin YJ, Barua A. Expression of P16 in high-risk human papillomavirus related lesions of the uterine cervix in a government hospital, Malaysia. Diagn Pathol. 2014;9:202.

18. Detorakis ET, Drakonaki EE, Spandidos DA. Molecular genetic alterations and viral presence in ophthalmic pterygium. Int J Mol Med. 2000;6:35-41.

19. McDonnell JM, McDonnell PJ, Sun YY. Human papillomavirus DNA in tissues and ocular surface swabs of patients with conjunctival epithelial neoplasia. Invest Ophthalmol Vis Sci. 1992;33:184-9.

20. Scott IU, Karp CL, Nuovo GJ. Human papillomavirus 16 and 18 expression in conjunctival intraepithelial neoplasia. Ophthalmology. 2002;109:542-7.

21. Ateenyi-Agaba C, Franceschi S, Wabwire-Mangen F, Arslan A, Othieno E, Binta-Kahwa J, et al. Human papillomavirus infection and squamous cell carcinoma of the conjunctiva. Br J Cancer. 2010;102:262-7.

22. Mwololo A, Nyagol J, Rogena E, Ochuk W, Kimani M, Onyango N, et al. Correlation of EGFR, pEGFR and p16INK4 expressions and high risk HPV infection in HIV/AIDS-related squamous cell carcinoma of conjunctiva. Infect Agent Cancer. 2014;9:7

23. Woods M, Chow S, Heng B, Glenn W, Whitaker N, Waring D, et al. Detecting human papillomavirus in ocular surface diseases. Invest Ophthalmol Vis Sci. 2013:54:8069-78.

24. Holladay EB, Logan S, Arnold J, Knesel B, Smith GD. A comparison of the clinical utility of p16(INK4a) immunolocalization with the presence of human papillomavirus by hybrid capture 2 for the detection of cervical dysplasia/neoplasia. Cancer. 2006;108:451-61.

25. Santos M, Landolfi S, Olivella A, Lloveras B, Klaustermeier J, Suarez H, et al. p16 overexpression identifies HPV-positive vulvar squamous cell carcinomas. Am J Surg Pathol. 2006;30:1347-56. 
26. Furth EE, Gustafson KS, Dai CY, Gibson SL, Menard-Katcher P, Chen T, et al. Induction of the tumor-suppressor p16(INK4a) within regenerative epithelial crypts in ulcerative colitis. Neoplasia. 2006;8:429-36.

27. Shao L, Feng W, Li H, Gardner D, Luo Y, Wang Y, et al. Total body irradiation causes long-term mouse BM injury via induction of HSC premature senescence in an Ink4a- and Arf-independent manner. Blood. 2014;123:3105-15.

28. Alexander RE, Hu Y, Kum JB, Montironi R, Lopez-Beltran A, Maclennan GT, et al. p16 expression is not associated with human papillomavirus in urinary bladder squamous cell carcinoma. Mod Pathol. 2012;25:1526-33.

29. Doxtader EE, Katzenstein AL. The relationship between p16 expression and high-risk human papillomavirus infection in squamous cell carcinomas from sites other than uterine cervix: a study of 137 cases. Hum Pathol. 2012;43:327-32.

30. Bouda M, Gorgoulis VG, Kastrinakis NG, Giannoudis A, Tsoli E, Danassi-Afentak D, et al. "High risk" HPV types are frequently detected in potentially malignant and malignant oral lesions, but not in normal oral mucosa. Mod Pathol. 2000;13:644-53.

31. Chernock RD, Wang X, Gao G, Lewis Jr JS, Zhang Q, Thorstad WL, et al. Detection and significance of human papillomavirus, CDKN2A(p16) and CDKN1A(p21) expression in squamous cell carcinoma of the larynx. Mod Pathol. 2013;26:223-31.

32. Lewis Jr JS, Chernock RD, Ma XJ, Flanagan JJ, Luo Y, Gao G, et al. Partial p16 staining in oropharyngeal squamous cell carcinoma: extent and pattern correlate with human papillomavirus RNA status. Mod Pathol. 2012;25:1212-20

33. Lewis Jr JS, Thorstad WL, Chernock RD, Haughey BH, Yip JH, Zhang Q, et al. p16 positive oropharyngeal squamous cell carcinoma:an entity with a favorable prognosis regardless of tumor HPV status. Am J Surg Pathol. 2010;34:1088-96

\section{Submit your next manuscript to BioMed Central and take full advantage of:}

- Convenient online submission

- Thorough peer review

- No space constraints or color figure charges

- Immediate publication on acceptance

- Inclusion in PubMed, CAS, Scopus and Google Scholar

- Research which is freely available for redistribution 